\title{
Neonatal near miss determinants at a maternity hospital for high-risk pregnancy in Northeastern Brazil: a prospective study
}

Telmo Henrique Barbosa de Lima ${ }^{1,2,5^{*}}$, Leila Katz ${ }^{3}$, Samir Buainain Kassar ${ }^{1}$ and Melania Maria Amorim ${ }^{3,4}$

\begin{abstract}
Background: To investigate the associations of maternal variables - sociodemographic, obstetrical and maternal near miss (MNM) variables - with neonatal near miss (NNM) using the new concept of NNM formulated by the Centro Latino-Americano de Perinatologia (CLAP) and the corresponding health indicators for NNM.

Methods: An analytical prospective cohort study was performed at maternity hospital for high-risk pregnancy in Northeastern Brazil. Puerperal women whose newborn infants met the selection criteria were subjected to interviews involving pretested questionnaires.

Statistical analysis was performed with the Epi Info 3.5.1 program using the Chi square test and Fisher's exact test when appropriate, with a level of significance of 5\%. A bivariate analysis was performed to evaluate differences between the groups. All the variables evaluated in the bivariate analysis were subsequently included in the multivariate analysis. For stepwise logistic regression analysis, a hierarchical model was plotted to assess variable responses and adverse outcomes associated with MNM and NNM variables.
\end{abstract}

Results: There were 1002 live births (LB) from June 2015 through May 2016, corresponding to 723 newborn infants (72.2\%) without any neonatal adverse outcomes, 221 (22\%) NNM cases, 44 (4.4\%) early neonatal deaths and 14 (1.4\%) late neonatal deaths. The incidence of NNM was 220/1000 LB. Following multivariate analysis, the factors that remained significantly associated with increased risk of NNM were fewer than 6 prenatal care visits (odds ratio (OR): 3.57; 95\% confidence interval (CI): 2.57-4.94) and fetal malformations (OR: 8.78; 95\% Cl: 3.69-20.90). Maternal age older than 35 years (OR: $0.43 ; 95 \% \mathrm{Cl}: 0.23-0.83$ ) and previous cesarean section (OR: $0.45 ; 95 \%$ Cl: $0.29-0.68)$ protected against NNM.

Conclusion: Based on the large differences between the NNM and neonatal mortality rates found in the present study and the fact that NNM seems to be a preventable precursor of neonatal death, we suggest that all cases of NNM should be audited. Inadequate prenatal care and fetal malformations increased the risk of NNM, while older maternal age and a history of a previous cesarean section were protective factors.

Keywords: Neonatal near miss, Neonatal mortality, Fetal death, Maternal near miss

\footnotetext{
* Correspondence: thbl@uol.com.br

${ }^{1}$ Health Sciences University of Alagoas (UNCISAL), Maceió, Brazil

${ }^{2}$ Health Sciences, Federal University of São Paulo (UNIFESP), São Paulo, Brazil

Full list of author information is available at the end of the article
}

(c) The Author(s). 2018 Open Access This article is distributed under the terms of the Creative Commons Attribution 4.0 International License (http://creativecommons.org/licenses/by/4.0/), which permits unrestricted use, distribution, and reproduction in any medium, provided you give appropriate credit to the original author(s) and the source, provide a link to the Creative Commons license, and indicate if changes were made. The Creative Commons Public Domain Dedication waiver (http://creativecommons.org/publicdomain/zero/1.0/) applies to the data made available in this article, unless otherwise stated. 


\section{Background}

One of the United Nations (UN) Millennium Development Goals (MDGs) was to reduce the child mortality rate by two-thirds. Brazil met this goal before 2015, with a more considerable reduction in postneonatal mortality and a slower reduction in early neonatal mortality; early neonatal mortality is currently the main component of child mortality [1].

As part of the UN Agenda for Sustainable Development, the goal for the period from 2016 to 2030 is to end preventable deaths of newborns and children under 5 years of age. For this purpose, all the countries that signed the UN document committed to reducing neonatal mortality to at least 12 per 1000 live births (LB) [2].

To assess and improve the quality of the care delivered to this population, reliable assessment instruments are necessary. Child mortality rate has long been used as a classic indicator of social development, economics and healthcare quality [3]. However, for each child who dies, many others survive serious complications; as in the case of maternal health, application of the near miss concept to the neonatal setting might be useful to detect risk factors for death, investigate the quality of care delivered to this population, strengthen the healthcare system and reduce the child mortality rate [4].

However, until recently, there has not been a standardized definition or any international criteria for detecting neonatal near miss (NNM) that would allow performing comparisons within the same institution over time or between different institutions in various regions or countries. In response to this scenario, in 2015, the Latin American Centre of Perinatology (Centro Latino-Americano de Perinatologia - CLAP) led discussions and proposals aiming at establishing a standardized definition of NNM [5] based on the results of previous studies on the subject [4-6]. The CLAP suggests defining NNM as any newborn infant who exhibited pragmatic and/or management criteria and survived the first 27 days of life.

Two studies have described the impact of maternal near miss (MNM) on fetal and neonatal mortality and associated factors and concluded that fetal and neonatal death rates are high among MNM patients $[7,8]$. It would seem logical for MNM to be strongly associated with NNM because their determinants - socioeconomic variables, demographic variables, reproductive history, health conditions during pregnancy, prenatal care and labor care - might be associated. However, we were not able to identify any study that investigated the association between these two conditions.

Therefore, the aim of the present study was to investigate the associations of maternal variables - sociodemographic, obstetrical and MNM variables - with NNM using the new concept of NNM formulated by the CLAP and to evaluate the corresponding health indicators for NNM.

\section{Methods}

The present prospective, analytical cohort study was conducted at Santa Monica Maternity School Hospital (Maternidade Escola Santa Mônica - MESM), which is located in Maceió, the capital of the state of Alagoas, in northeastern Brazil. MESM had the lowest Human Development Index (HDI) of 0.631 in the country in 2016 . MESM is a public maternity hospital for women with high-risk pregnancies. It is the main obstetrical and neonatal referral center for highly complex cases in Alagoas, and approximately $50 \%$ of women with high-risk pregnancies in the state receive care at MESM.

Data collection was performed from June 2015 through May 2016 by the principal investigator and research assistants who were students of an undergraduate medical course and had received specific training for the study. The study was approved by the Human Research Ethics Committee of Universidade Estadual de Ciências da Saúde de Alagoas (UNCISAL) (CAAE no. 37977014.0.0000.5011). All the included women or their legally responsible parties were approached on the day after delivery by the researcher or one of the assistants and invited to participate in the study. They were included only after voluntarily agreeing to participate and signing an informed consent form.

The outcome variable was NNM, and the exposure variables were age, race, marital status, education level, origin, family income, prenatal care, number of prenatal visits, prenatal care performed at the hospital, household visits, current pregnancy, previous cesarean section, referral for childbirth, previous pregnancies, maternal admission to an intensive care unit (ICU), fetal presentation, smoking history, fetal malformations, comorbidities and MNM.

NNM was defined as a neonate who had suffered a life-threatening condition but survived the first 27 days of life [5]. Two sets of criteria that are recommended by the CLAP were used to identify newborn infants at a high risk of death at birth: pragmatic criteria (gestational age at birth less than 33 weeks; birth weight $<1750$ g; and 5-min Apgar score $<7$ ) and management criteria (parenteral antibiotics for up to 7 days before 28 days of age; use of a continuous positive airway pressure (CPAP) device; any intubation lasting for up to 7 days before 28 days of age; phototherapy within the first $24 \mathrm{~h}$ of life; cardiopulmonary resuscitation; use of vasoactive drugs, anticonvulsants, surfactant, or blood-derived products or use of steroids to treat refractory hypoglycemia; and any surgical procedure) [5].

Some indicators of perinatal care quality were calculated [5]: early neonatal mortality rate (ENMR), neonatal mortality rate (NMR), neonatal near miss rate (NNMR), early severe neonatal outcome rate (ESNOR), severe neonatal outcome rate (SNOR), and lethality ratio. 
MNM was defined as a woman who survived a severe, life-threatening complication during pregnancy, childbirth or within 42 days of termination of pregnancy and met any of the clinical, laboratory or management criteria formulated by the World Health Organization (WHO) [9].

Puerperal women whose newborn infants met the selection criteria were subjected to interviews involving pretested questionnaires; other relevant information was obtained from medical records. The data for the newborn infants were collected during the immediate postpartum period and from their medical records. A second interview (by phone call or a home visit) was performed 42 days after childbirth to assess maternal and neonatal outcomes.

Data were collected on printed forms that were stored in the hospital until the final maternal and neonatal outcomes were assessed. Data were then entered into a database created specifically for this purpose in the statistical program Epi Info 3.5.1 (Atlanta, GA), in which the statistical analysis was performed. The data were entered twice and compared, and inconsistencies were corrected. In the bivariate analysis, NNM was the outcome variable, and the aforementioned exposure variables were dichotomized as yes/no variables. The risk ratio (RR) was estimated as a measure of risk, with the corresponding 95\% confidence interval (95\% CI). The Chi square test or Fisher's exact test was used as necessary.

All the variables considered for the bivariate analysis were included in a multiple logistic regression analysis to identify the variables that were most strongly associated with NNM, and the adjusted risk was calculated. A hierarchical model was plotted for multiple regression analysis; the variables were included in blocks according to risk categories, and biological and socioeconomic variables including race/skin color (nonwhite), educational level (less than 8 years of schooling), origin (inner state), income (less than the minimum wage), age (younger than 20 years old), age (older than 35 years old) and marital status (without a partner) were the most distal factors. In the intermediate level, variables corresponding to prenatal and labor care were included: no prenatal care, fewer than 6 prenatal care visits, prenatal care not performed at the hospital where the study was conducted, no referral to a maternity hospital for childbirth, previous cesarean section, nulliparity, noncephalic presentation, maternal admission to an ICU and smoking history. Variables that were considered to be closest to the outcome of NNM were included in the proximal level: comorbidities, MNM (clinical, laboratory and management criteria) and fetal malformations.

Stepwise logistic regression was performed; at the end of each block, the variables associated with the outcome at a $20 \%$ significance level were selected, followed by those that remained associated with the outcome at a
5\% significance level. A final regression analysis was then performed to determine the adjusted risk for NNM for each of the variables that were significantly associated with the outcome at a $5 \%$ significance level. Odds ratios (ORs) and corresponding 95\% CIs were calculated for these variables.

\section{Results}

From June 2015 to May 2016, 1149 women were admitted to the maternity ward. Thirty-four had miscarriages, and 21 delivered stillborn infants. The initial interview was performed with 1094 women on the first postpartum day, and when they were invited, all of them consented to participate. After initial inclusion, during the follow-up period, 44 newborns (4.4\%) were early neonatal deaths, and $14(1.4 \%)$ were late neonatal deaths. Of the 1002 LB that could be analyzed, 58 newborns were lost to follow-up; thus, 723 babies that did not exhibit any neonatal adverse outcomes (72.2\%) and 221 (22\%) NNM cases were included (Fig. 1).

Indicators of perinatal care quality were calculated for the aforementioned period, resulting in 220 NNM cases/ 1000 LB, a SNOR of 278/1000 LB and an NMR of 57/ 1000 LB (Table 1).

A total of 131 newborn infants met the pragmatic criteria for NNM, corresponding to an incidence of 131/ 1000 LB. Among the pragmatic criteria, gestational age younger than 33 weeks (47.5\%) was the most commonly identified criterion, with an incidence of 105/1000 LB.

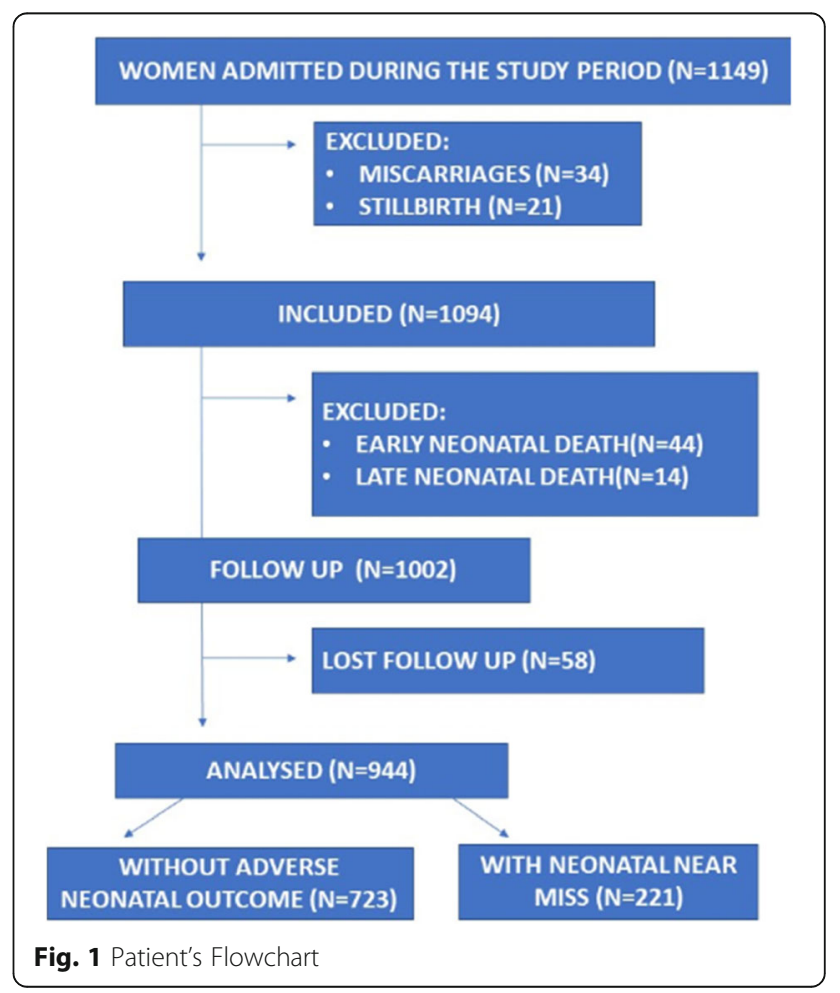


Table 1 Indicators of perinatal outcomes

\begin{tabular}{lrl}
\hline Indicators & No. & Rate \\
\hline Number of live births & 1002 & \\
Early neonatal deaths & 44 & \\
Late neonatal deaths & 14 & \\
Newborn infants with neonatal near miss & 221 & \\
Neonatal near miss rate & & 220/1000 LB \\
Early severe neonatal outcome rate & $264 / 1000$ LB \\
Severe neonatal outcome rate & 278/1000 LB \\
Early neonatal mortality rate & & $44 / 1000$ LB \\
Neonatal mortality rate (early + late) & & $57 / 1000$ LB \\
Lethality ratio & 3.8 & \\
\hline
\end{tabular}

All 221 newborn infants met the management criteria, corresponding to an incidence of $220 / 1000 \mathrm{LB}$; the use of a nasal CPAP device was the most commonly identified criterion (62.9\%), with an incidence of 139/1000 LB (Table 2). Ninety newborn infants presented only the management criteria, while the remaining infants had both pragmatic and management criteria.

In the hierarchical bivariate analysis, the sociodemographic, obstetrical and MNM variables that exhibited statistically significant associations with NNM were age younger than 20 years $(R R=1.58 ; 95 \% C I=1.25-1.99)$, age older than 35 years $(R R=0.37 ; 95 \% C I=0.21-0.64)$, fewer than 6 prenatal care visits $(\mathrm{RR}=2.63$; $95 \% \mathrm{CI}=$ $2.08-3.33)$, no referral for childbirth $(R R=1.49 ; 95 \%$ $\mathrm{CI}=1.15-1.94)$, history of a previous cesarean section

Table 2 Criteria for neonatal near miss

\begin{tabular}{|c|c|c|c|}
\hline Criteria & No. & $\%$ & $\begin{array}{l}\text { Incidence of neonatal } \\
\text { near miss/1000 LB }\end{array}$ \\
\hline Pragmatic criteria & 131 & 59.3 & 131.2 \\
\hline Gestational age $<33$ weeks & 105 & 47.5 & 105.2 \\
\hline Weight $(<1750 \mathrm{~g})$ & 99 & 44.8 & 99.1 \\
\hline 5-min Apgar score $(<7)$ & 15 & 6.8 & 15.0 \\
\hline Management criteria & 221 & 100.0 & 220.0 \\
\hline $\begin{array}{l}\text { Nasal continuous positive } \\
\text { airway pressure }\end{array}$ & 139 & 62.9 & 139.2 \\
\hline Surfactant & 100 & 45.2 & 100.2 \\
\hline Intubation & 84 & 38.0 & 84.1 \\
\hline Parenteral antibiotics & 67 & 30.3 & 67.1 \\
\hline Blood-derived products & 41 & 18.6 & 41.0 \\
\hline Phototherapy during the first $24 \mathrm{~h}$ & 22 & 10.0 & 22.0 \\
\hline Vasoactive drugs & 11 & 5.0 & 11.0 \\
\hline Surgical procedures & 11 & 4.9 & 11.0 \\
\hline Anticonvulsants & 7 & 3.2 & 7.0 \\
\hline Cardiopulmonary resuscitation & 05 & 2.3 & 5.1 \\
\hline Steroids for hypoglycemia & 01 & 0.5 & 1.0 \\
\hline
\end{tabular}

$(\mathrm{RR}=0.52 ; 95 \% \quad \mathrm{CI}=0.37-0.73)$, nulliparity $\quad(\mathrm{RR}=1.31$; $95 \% \mathrm{CI}=1.04-1.65)$, noncephalic presentation $(\mathrm{RR}=1.78$; $95 \% \mathrm{CI}=1.30-2.44)$, maternal admission to an ICU (RR = $1.64 ; 95 \% \mathrm{CI}=1.17-2.28)$, fetal malformations $(\mathrm{RR}=3.07$; 95\% CI $=2.32-4.08)$, MNM $(\mathrm{RR}=1.94 ; 95 \% \mathrm{CI}=1.31-$ $2.89)$, clinical criteria for $\mathrm{MNM}(\mathrm{RR}=1.99$; $95 \% \mathrm{CI}=$ 1.32-2.98) and management criteria for $\mathrm{MNM}(\mathrm{RR}=1.86$; 95\% CI = 1.12-3.1) (Table 3).

All the variables assessed in the bivariate analysis were included in a multivariate analysis involving a logistic regression model with hierarchical levels. The factors that remained significantly associated with a higher risk of NNM were fewer than 6 prenatal care visits $(\mathrm{OR}=3.57$; $95 \% \mathrm{CI}=2.57-4.94)$ and the presence of fetal malformations $(\mathrm{OR}=8.78 ; 95 \% \mathrm{CI}=3.69-20.90)$, while maternal age older 35 years $(\mathrm{OR}=0.43 ; 95 \% \mathrm{CI}=0.23-0.83)$ and history of a previous cesarean section $(\mathrm{OR}=0.45$; $95 \%$ $\mathrm{CI}=0.29-0.68$ ) were protective against NNM (Table 4 ).

\section{Discussion}

In this study, the incidence of NNM was 220/1000 LB. Following multivariate analysis, the factors that remained significantly associated with a higher risk of NNM were fewer than six prenatal care visits and the presence of fetal malformations, while maternal age older than 35 years and previous cesarean section were protective factors against NNM.

We conducted an active search of the PubMed, Biblioteca Regional de Medicina (BIREME) and Scopus databases. This study is the first to analyze the association between MNM and the severe neonatal condition NNM with prospectively collected data and the use of the 2015 CLAP criteria [5] to define NNM in an attempt to standardize the definition of NNM and to facilitate comparisons of NNM rates between different regions and countries.

In our study, NNM accounted for $79.2 \%$ of the adverse perinatal outcomes; this NNM rate was 3.8 times higher than the NMR. In other studies, the NNM rate varied from 2.6- to 8-fold higher than the NMR, even when the same criteria and markers were used $[4,6,10,11]$.

The high NNM rate (220/1000 LB) and NMR (57/ $1000 \mathrm{LB})$ found in the present study differ from those in other reports (21.4-72.5/1000 LB and 6.3-11.1/1000 LB, respectively) $[4,6,10,11]$. These differences might be attributable to the fact that the present study considered the associations of pragmatic (59.3\%) and management $(40.7 \%)$ criteria. Several studies have shown that the combination of these criteria exhibits better performance than either set of criteria used alone, with sensitivities and specificities of almost 93\% [5, 12]; the use of this combination of criteria allowed us to assess a larger number of surviving newborn infants. Another reason that might explain the high NNM rate and NMR found in the present study is that other authors employed 
Table 3 Associations of sociodemographic and obstetrical variables and maternal near miss with neonatal near miss

\begin{tabular}{|c|c|c|c|c|}
\hline & \multicolumn{2}{|c|}{ Neonatal near miss } & \multirow[t]{2}{*}{ RR $(95 \% \mathrm{Cl})$} & \multirow[t]{2}{*}{$P$} \\
\hline & Yes, n (\%) & No, n (\%) & & \\
\hline \multicolumn{5}{|l|}{ Distal factors } \\
\hline Race/skin color (nonwhite) & $170(76.9)$ & $583(80.6)$ & $0.84(0.64-1.10)$ & 0.22 \\
\hline Education level (< 8 years) & $121(54.8)$ & $385(53.3)$ & $1.04(0.83-1.32)$ & 0.69 \\
\hline Origin (inner state) & $116(52.5)$ & $359(49.7)$ & $1.09(0.86-1.37)$ & 0.46 \\
\hline Income (< minimum wage) & 185(83.7) & $571(79.0)$ & $1.27(0.92-1.75)$ & 0.12 \\
\hline Age $(<20$ years old $)$ & $86(38.9)$ & 185(25.6) & $1.58(1.25-1.99)$ & 0.0001 \\
\hline Age (> 35 years old) & $12(5.4)$ & 114(15.8) & $0.37(0.21-0.64)$ & 0.00007 \\
\hline Marital status (without a partner) & $54(24.4)$ & $141(19.5)$ & $1.24(0.95-1.61)$ & 0.11 \\
\hline \multicolumn{5}{|l|}{ Intermediate factors } \\
\hline No prenatal care & $6(2.7)$ & $11(1.5)$ & $1.52(0.79-2.92)$ & $0.18^{*}$ \\
\hline$<6$ prenatal care visits & $133(60.2)$ & $211(29.2)$ & $2.63(2.08-3.33)$ & $<0.0000001$ \\
\hline Prenatal care at service & 179(81.0) & $544(75.2)$ & $1.30(0.96-1.75)$ & 0.07 \\
\hline No household visits & 219(99.1) & $698(96.5)$ & $3.22(0.84-12.29)$ & 0.04 \\
\hline No referral for childbirth & $160(72.4)$ & $441(61.0)$ & $1.49(1.15-1.94)$ & 0.002 \\
\hline Current pregnancy (cesarean section) & $165(74.7)$ & $548(75.8)$ & $0.95(0.73-1.24)$ & 0.73 \\
\hline Previous cesarean section & $35(15.8)$ & 214(29.6) & $0.52(0.37-0.73)$ & 0.00004 \\
\hline Nulliparity & 112(50.7) & $302(41.8)$ & $1.31(1.04-1.65)$ & 0.01 \\
\hline Noncephalic presentation & $28(12.7)$ & $43(6.0)$ & $1.78(1.30-2.44)$ & 0.0009 \\
\hline Admission to an intensive care unit & 25(11.3) & $43(5.9)$ & $1.64(1.17-2.28)$ & 0.006 \\
\hline Smoker & $9(4.2)$ & $20(2.7)$ & $1.33(076-2.33)$ & 0.32 \\
\hline \multicolumn{5}{|l|}{ Proximal factors } \\
\hline Fetal malformation & 19(8.6) & $9(1.2)$ & $3.07(2.32-4.08)$ & $<0.0000001$ \\
\hline Comorbidities & $78(35.3)$ & $306(42.3)$ & $0.79(0.62-1.01)$ & 0.06 \\
\hline Maternal near miss & $15(6.7)$ & $19(2.6)$ & $1.94(1.31-2.89)$ & 0.003 \\
\hline Maternal near miss clinical criteria & $14(6.3)$ & $17(2.3)$ & $1.99(1.32-2.98)$ & 0.003 \\
\hline Maternal near miss laboratory criteria & $05(2.2)$ & $9(1.2)$ & $1.53(0.75-3.13)$ & $0.42^{*}$ \\
\hline Maternal near miss management criteria & $09(4.0)$ & $12(1.7)$ & $1.86(1.12-3.1)$ & $0.07^{*}$ \\
\hline
\end{tabular}

"Analysis performed with Fisher's exact test

Table 4 Multivariate analysis of neonatal near miss determinants

\begin{tabular}{llll}
\hline & OR & $95 \% \mathrm{Cl}$ & $P$ \\
\hline $\begin{array}{l}\text { Distal factors } \\
\quad \text { Age (> 35 years old) }\end{array}$ & 0.43 & $0.23-0.83$ & 0.0118 \\
$\begin{array}{l}\text { Intermediate factors } \\
\quad \text { Previous cesarean section (yes) }\end{array}$ & 0.45 & $0.29-0.68$ & 0.0002 \\
$\quad<6$ prenatal care visits & 3.57 & $2.57-4.94$ & 0.0000 \\
$\begin{array}{l}\text { Proximal factors } \\
\quad \text { Fetal malformation (yes) }\end{array}$ & 8.78 & $3.69-20.90$ & 0.0000 \\
\hline
\end{tabular}

population databases $[4,6,10,11]$, while the present study used only data from a maternity hospital that is a referral center for women with high-risk pregnancies; this sample selection was a source of bias that resulted in high frequencies of adverse outcomes. In addition, the observation period in our study was 28 days, while in other studies, it varied from 3 to 28 days after birth [4, $6,10,11]$ thus limiting the assessment of the quality of late neonatal care and neonatal mortality. By selecting a prospective design in which neonatal complications were monitored on a daily basis, we possibly avoided the losses that might occur in studies involving retrospective databases. Finally, the high NNM rate and NMR found might be related to the socioeconomic status of the state of Alagoas, which has the lowest HDI in Brazil.

Currently, comparison of the NNM rates of different hospitals is difficult due to the lack of a universally 
accepted definition of NNM, as there is for MNM [9]. In response to this scenario, in 2015, the CLAP guided a series of discussions and proposals to develop a consensus definition of NNM based on pragmatic and management criteria [5].

The management criteria for NNM cannot be used to compare the quality of healthcare between different hospitals because the NNM rate might be influenced by the technological complexity of the services provided [12], unless a general complexity index is developed and included in the statistical analysis [11]. Thus, the best option to detect NNM cases in hospitals with more substantial resources, such as ICUs and neonatal ICUs, as in the maternity hospital where the present study was conducted, is to combine the pragmatic and management criteria $[5,12]$.

As NNM is known to be a useful assessment of the quality of obstetrical and neonatal care $[4-6,10,11]$, we sought to investigate whether maternal variables (sociodemographic, obstetrical and MNM variables) were related to NNM.

Multivariate analysis provided two results that diverged from those of other reports in the literature in terms of age extremes. First, age younger 20 years did not exhibit an association with NNM, although adolescent pregnancy is usually associated with poorer maternal and perinatal outcomes including prematurity, low birth weight and occurrence of 5-min Apgar scores of less than 7, than pregnancy in adult women [3, 13-15]. Other mechanisms that are not biological might mediate the relationships between adolescence and adverse obstetric/perinatal outcomes, which previous studies failed to detect.

Age older than 35 years exhibited a statistically significant association with NNM in the multivariate analysis, demonstrating evidence of a protective effect. This finding is in clear contrast with those of previous reports on age extremes and perinatal outcomes $[3,15]$. The data on the risk associated with pregnancy at an age older than 35 years are conflicting due to the presence of other variables, such as parity and pre-existing diseases, which impair assessment of the risk associated with maternal age alone [16]. However, in the present study, we ruled out confounding variables; thus, the results might be explained by the fact that currently, most pregnancies among women older than 35 years are planned, and prenatal and required care are prioritized, leading to consequent improvement in perinatal outcomes. Alternatively, when caring for older pregnant women with or without associated diseases, healthcare providers might be more alert and intervene earlier in these women than in younger pregnant women, thus preventing adverse outcomes. Therefore, the results described here might pave the way for new studies.
Prenatal care is important. In theory, more prenatal visits might mean higher odds of receiving care, especially in the case of high-risk pregnancy, which is associated with poor maternal and perinatal outcomes. In Brazil, the prenatal care coverage and number of visits have increased over the past 15 years [17]. However, studies conducted in the country have still revealed flaws in prenatal care, such as difficult access to care, late onset of care, an inadequate number of visits and incomplete performance of procedures, all of which impact perinatal outcomes [18-20]. Such outcomes are below the country's potential and reflect unfavorable living and healthcare conditions, in addition to historical regional and socioeconomic inequalities [3].

Our findings confirm the deleterious effects of inadequate prenatal care. Attending fewer than 6 prenatal care visits was statistically significantly associated with NNM, increasing the risk of NNM by 4-fold. The nationwide hospital-based survey Birth in Brazil, which was conducted in 2014, analyzed neonatal mortality profiles and found high NNM rates among mothers who received inadequate prenatal care [3]. The underlying causes of most neonatal deaths are maternal obstetrical problems that were not resolved prenatally [21]. Therefore, the prenatal care coverage needs to be broadened, and the quality of the care delivered improved, especially for women with high-risk pregnancies.

Women with a history of a previous cesarean section are more often subjected to a second cesarean section because many obstetricians still base their decision-making on a principle that was formulated in 1916, according to which "once a C-section, always a C-section," and fear rupture of uterine scars [22]. However, there is no scientific evidence supporting this alleged risk, as uterine scar rupture occurs in approximately $1 \%$ of patients [23]. In our study, $94.3 \%$ of women with a history of a previous cesarean section were again subjected to cesarean section. In the multivariate analysis, this variable was protective against NNM. The presence of a previous uterine scar might have led to the decision to perform a cesarean section early in the course of labor, and some of the newborn infants might have benefited from the fact that $33.9 \%$ of the mothers had high-risk pregnancies that required urgent resolution. Adverse events derived from the lack of rigorous monitoring during labor, which is essential in women with a history of a previous cesarean section, might have been avoided; thus, cesarean section was a protective factor because maternal complications that contribute to the occurrence of adverse perinatal outcomes were prevented.

In one study published in 2017, the survival of newborn infants born to mothers without severe complications was better than that of infants born to mothers 
with eclampsia, intrapartum hemorrhage or other complications requiring ICU admission [15]. In the multivariate analysis performed in the present study, maternal ICU admission did not remain associated with NNM. Perhaps this marker of maternal severity is not always a marker of neonatal severity and vice versa. For instance, conditions such as puerperal sepsis or hemorrhage do not affect the newborn infant, even though the mother needs to be admitted to an ICU; in the case of spontaneous premature labor, the infant might be an NNM case, although the mother is not an MNM case.

Newborn infants with congenital malformations exhibited a 9-fold increased risk of NNM; this result remained unchanged after controlling for confounding variables. This finding was expected because fetal malformations increase neonatal morbidity and mortality. The literature shows that despite high-quality interventions, in most of these infants, neonatal death due to several fetal malformations cannot be avoided [12]. This variable has been rarely investigated in previous studies $[5,12]$ and seems to be a relevant marker for characterizing NNM cases; thus, it should be employed in future studies as a defining criterion for NNM.

Studies on MNM are abundant in the literature [24, 25], especially after 2009 , following a publication on the definition of and criteria for MNM formulated by the WHO [9]. However, we were not able to locate any study reporting an association between MNM and NNM.

Two studies investigated the relationship between MNM and adverse perinatal outcomes (fetal and neonatal deaths) $[7,8]$. In the first study performed in 2013, the authors found high frequencies of fetal and neonatal deaths among MNM cases, and the main factors associated with outcomes were severe pre-eclampsia, placental abruption, prematurity and endometritis; there was also an association between laboratory criteria and adverse outcomes [7]. These results were corroborated by a second study that was performed in 2017 [8].

It would seem logical for NNM to be strongly associated with MNM because the determinants (socioeconomic variables, demographic variables, reproductive history, health status during pregnancy, prenatal care and labor care) might also be associated. However, the multivariate analysis did not reveal an association between MNM variables and NNM outcomes. A possible explanation is that many of the conditions that lead to the classification of a woman as an MNM case are so severe that they lead to early resolution of pregnancy thus sparing the fetus from complications. Alternatively, many of the conditions for which a woman is classified as an MNM case, such as puerperal hemorrhage and sepsis, occur after birth, again sparing the fetus from complications.

Among the strengths of the present study are its prospective cohort design and the fact that a multiple regression model that accounted for the mutual interrelationships of variables was used; thus, potential confounding variables were controlled. In addition, this is one of the first studies to employ the CLAP criteria to define NNM and to investigate the impact of maternal factors on NNM and the association between MNM and NNM, both of which have rarely been analyzed in the literature.

Some limitations of the present study are derived from the fact that NNM was assessed at a hospital for women with high-risk pregnancies; thus, the study sample is not representative of the population of pregnant women in Alagoas. In addition, the data corresponding to socioeconomic variables and access to healthcare were collected in interviews conducted with the participants and might be subject to recall bias.

\section{Conclusion}

Based on the large differences between the NNM rate and NMR found in the present study and the fact that NNM seems to be a preventable precursor of neonatal death, we suggest that all cases of NNM should be audited. Inadequate prenatal care and fetal malformations increased the risk of NNM, while older maternal age and a history of previous cesarean section were protective factors.

\section{Abbreviations}

CLAP: Latin American Centre of Perinatology (Centro Latino-Americano de Perinatologia); ENMR: Early neonatal mortality rate; ESNOR: Early severe neonatal outcome rate; HDI: Human Development Index; ICU: Intensive care unit; LB: Live births; MDGs: Millennium Development Goals; MESM: Santa Monica Maternity School Hospital (Maternidade Escola Santa Mônica); MNM: Maternal near miss; NMR: Neonatal mortality rate; NNM: Neonatal near miss; NNMR: Neonatal near miss rate; OR: Odds ratio; RR: Risk ratio; SNOR: Severe neonatal outcome rate; SUS: Unified Heath System (Sistema Único de Saúde); UN: United Nations; UNCISAL: State University of Health Sciences of Alagoas (Universidade Estadual de Ciências da Saúde de Alagoas); WHO: World Health Organization

\section{Acknowledgments}

To all the women who agreed to participate in the study with their newborn infants, for believing in the potential of research to transform everyday clinical practice, our most sincere thanks.

Study conducted at Maternidade Escola Santa Mônica, Avenida Comendador Leão, SN, Poço, Maceió/AL, Brazil.

\section{Funding}

The present study did not have any specific funding.

\section{Availability of data and materials}

The data and material are with the corresponding author (Telmo Henrique Barbosa de Lima - E-mail: thbl@uol.com.br).

\section{Authors' contributions}

THBL and SBK designed the initial project, which was revised by LK and MMA. THBL was responsible for the data collection. SBK, THBL and LK performed the statistical analysis. THBL wrote the manuscript draft, which was revised by LK, SBK and MMA. All authors read and approved the final version of the manuscript.

Ethics approval and consent to participate

The study was approved by the Research Ethics Committee of Alagoas State Health Sciences University (Universidade Estadual de Ciências da Saúde de 
Alagoas - UNICISAL; CAAE no. 37977014.0.0000.5011) on 5 March 2015. All the participants signed an informed consent form; participation was voluntary. We clarified that some of the participants involved in the study were younger than 16 years of age and that written consent was obtained from a parent or legal guardian on behalf of those participants who were under the age of 16

\section{Consent for publication}

Not applicable.

\section{Competing interests}

The authors declare that they have no competing interests.

\section{Publisher's Note}

Springer Nature remains neutral with regard to jurisdictional claims in published maps and institutional affiliations.

\section{Author details}

${ }^{1}$ Health Sciences University of Alagoas (UNCISAL), Maceió, Brazil. ${ }^{2}$ Health Sciences, Federal University of São Paulo (UNIFESP), São Paulo, Brazil. ${ }^{3}$ Postgraduate Program, Fernando Figueira Institute of Integral Medicine (IMIP), Obstetric Intensive Care Unit, IMIP, Recife, Brazil. ${ }^{4}$ Federal University of Campina Grande (UFCG), Campina Grande, Brazil. ${ }^{5}$ Maternidade Santa Mônica, Maceió, Brazil

Received: 17 March 2018 Accepted: 23 September 2018

Published online: 12 October 2018

\section{References}

1. Brasil, Ministério da Saúde. Reduzindo a mortalidade perinatal [Reducing perinatal mortality]; 2016. [cited 2016 Dec 17]. Available from: http://brasil. evipnet.org/wp-content/uploads/2016/07/Mortalidade_perinatal_WEB_jul.pdf

2. WHO - World Health Organization. Maternal mortality. Fact sheet no.348; 2015. [cited 2015 Dec 17] Available from: http://www.who.int/mediacentre/ factsheets/fs348/en/.

3. Lansky S, Friche AADL, Silva AAMD, Campos D, Bittencourt SDDA, Carvalho $\mathrm{ML}$, et al. Pesquisa nascer no Brasil: perfil da mortalidade neonatal e avaliação da assistência à gestante e ao recém-nascido [Birth in Brazil survey: neonatal mortality, pregnancy and childbirth quality of care]. Cad Saude Publica. 2014;30(suppl 1):S192-207.

4. Pileggi C, Souza JP, Cecatti JG, Faúndes A. Neonatal near miss approach in the 2005 WHO global survey Brazil. J Pediatr. 2010;86(1):21-6.

5. Santos JP, Cecatti JG, Serruya SJ, Almeida PV, Duran P, Mucio B, et al. Neonatal near miss: the need for a standard definition and appropriate criteria and the rationale for a prospective surveillance system. Clinics. 2015;70(12):820-6.

6. Pileggi-Castro C, Camelo JS, Perdoná GC, Mussi-Pinhata MM, Cecatti JG, Mori R, et al. Development of criteria for identifying neonatal near-miss cases: analysis of two WHO multicountry cross-sectional studies. BJOG. 2014; 121(Suppl 1):110-8.

7. Oliveira LC, Costa AAR. Óbitos fetais e neonatais entre casos de near miss materno [fetal and neonatal deaths among cases of maternal near miss] Rev Assoc Med Bras. 2013;59(5):487-94.

8. Nardello DM, Guimarães AMDAN, Barreto IDC, Gurgel RQ, Ribeiro ERO, Gois CFL. Fetal and neonatal deaths of children of patients classified as near miss. Rev Bras Enferm. 2017;70(1):98-105.

9. Say L, Souza JP, Pattinson RC. Maternal near miss - towards a standard tool for monitoring quality of maternal health care. Best Pract Res Clin Obstet Gynaecol. 2009;23(3):287-96.

10. Avenant T. Neonatal near miss: a measure of the quality of obstetric care. Best Pract Res Clin Obstet Gynaecol. 2009;23(3):369-74.

11. Silva AAMD, Leite ÁJM, Lamy ZC, Moreira MEL, Gurgel RQ, Cunha AJLA, et al. Morbidade neonatal near miss na pesquisa nascer no Brasil [neonatal near miss in the birth in Brazil survey]. Cad Saude Publica. 2014;30(suppl 1):S182-91.

12. Santos JP, Pileggi-Castro C, Camelo JS, Silva AA, Duran P, Serruya SJ, et al. Neonatal near miss: a systematic review. BMC Pregnancy Childbirth. 2015; 15(1):320

13. Morcillo AM, Carniel EDF, Zanolli MDL, Moreno LZ, Antonio MÂRGM Caracterização das mães, partos e recém-nascidos em Campinas, São Paulo, 2001 e 2005 [Characterization of mothers, mode of deliveries and newborns in Campinas, São Paulo, 2001 and 2005]. Rev Paul Pediatr. 2010; 28(3):269-75.
14. Partridge S, Balayla J, Holcroft C, Abenhaim H. Inadequate prenatal care utilization and risks of infant mortality and poor birth outcome: a retrospective analysis of $28,729,765$ U.S. deliveries over 8 years. Am J Perinatol. 2012;29(10):787-94.

15. Anggondowati T, El-Mohandes AAE, Qomariyah SN, Kiely M, Ryon JJ, Gipson RF, et al. Maternal characteristics and obstetrical complications impact neonatal outcomes in Indonesia: a prospective study. BMC Pregnancy Childbirth. 2017;17(1):100.

16. Takagi MM, Jorge SRPF, Rodrigues LDP, Yamano LM, Piato S, Aoki T. Perinatal results in pregnant women with more than 35 years. Arq Med Hosp Fac Cienc Med Santa Casa São Paulo. 2010:55(3):108-14.

17. Viellas EF, Domingues RMSM, Dias MAB, Gama SGND, Filha MMT, Costa JVD, et al. Assistência pré-natal no Brasil [Prenatal care in Brazil]. Cad Saude Publica. 2014;30(suppl 1):S85-100.

18. Saavedra JS, Cesar JA. Uso de diferentes critérios para avaliação da inadequação do pré-natal: um estudo de base populacional no extremo Sul do Brasil [Use of different criteria to assess inadequate prenatal care: a population-based study in Southern Brazil]. Cad Saude Publica. 2015;31(5):1003-14

19. Domingues RMSM, Hartz ZMDA, Dias MAB, Leal MDC. Avaliação da adequação da assistência pré-natal na rede sus do município do Rio de Janeiro, Brasil [Adequacy of prenatal care in the national health system in the city of Rio de Janeiro, Brazil]. Cad Saude Publica. 2012;28(3):425-37.

20. Nunes JT, Gomes KRO, Rodrigues MTP, Mascarenhas MDM. Qualidade da assistência pré-natal no Brasil: revisão de artigos publicados de 2005 a 2015 [Quality of prenatal care in Brazil: review of published papers from 2005 to 2015]. Cad Saude Colet. 2016:24(2):252-61.

21. Pedrosa LDCO, Sarinho SW, Ordonha MR. Análise da qualidade da informação sobre causa básica de óbitos neonatais registrados no sistema de informações sobre mortalidade: um estudo para Maceió, Alagoas, Brasil, 2001-2002 [Quality of information analysis on basic causes of neonatal deaths recorded in the mortality information system: a study in Maceióa, Alagoas State Brazil, 2001-2002]. Cad Saude Publica. 2007;23(10):2385-95.

22. Ugwumadu A. Does the maxim "once a caesarean, always a caesarean" still hold true? PLoS Med. 2005;2(9):e305.

23. Nair M, Soffer K, Noor N, Knight M, Griffiths M. Selected maternal morbidities in women with a prior caesarean delivery planning vaginal birth or elective repeat caesarean section: a retrospective cohort analysis using data from the UK obstetric surveillance system. BMJ Open. 2015;5(6):e007434.

24. Domingues RMSM, Dias MAB, Schilithz AOC, Leal MDC. Factors associated with maternal near miss in childbirth and the postpartum period: findings from the birth in Brazil national survey, 2011-2012. Reprod Health. 2016. 13(S3): 115.

25. Tunçalp Ö, Hindin MJ, Souza JP, Chou D, Say L. The prevalence of maternal near miss: a systematic review. BJOG. 2012;119(6):653-61.

\section{Ready to submit your research? Choose BMC and benefit from:}

- fast, convenient online submission

- thorough peer review by experienced researchers in your field

- rapid publication on acceptance

- support for research data, including large and complex data types

- gold Open Access which fosters wider collaboration and increased citations

- maximum visibility for your research: over $100 \mathrm{M}$ website views per year

At $\mathrm{BMC}$, research is always in progress.

Learn more biomedcentral.com/submission 